
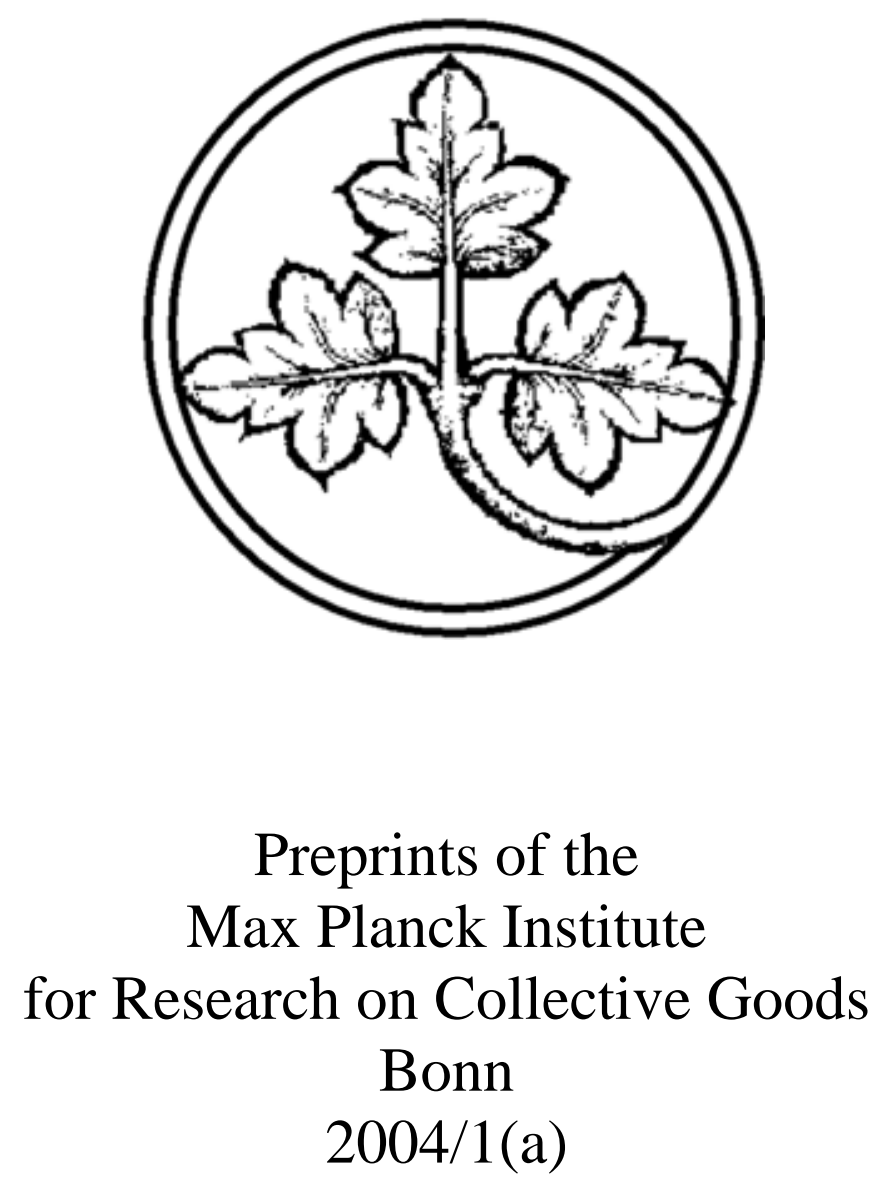

The Institutional-Evolutionary Antitrust Model

C. Mantzavinos 


\title{
The Institutional-Evolutionary Antitrust Model
}

\section{Mantzavinos*}

\begin{abstract}
The purpose of this article is to provide an alternative antitrust model to the mainstream model that is used in competition policy. I call it the Institutional-Evolutionary Antitrust Model. In order to construct an antitrust model one needs both empirical knowledge and considerations of how to adequately deal with norms. The analysis of competition as an evolutionary process that unfolds within legal rules provides the empirical foundation for the model. The development of the normative dimension involves the elaboration of a comparative approach. Building on those foundations the main features of the Institutional-Evolutionary Model are sketched out and it is shown that its use leads to systematically different outcomes and conclusions than the dominant antitrust ideals.
\end{abstract}

Keywords: Antitrust, Competition, Competition Policy, Evolutionary Process, Institutions

Address: Max Planck Institute for Research on Collective Goods, Kurt Schumacher Str. 10, 53113 Bonn, Germany, Tel.: +49 228 9141679, Fax.: +49 228 9141688,

e-mail: mantzavinos@mpp-rdg.mpg.de 


\section{Introduction}

"Only through the principle of competition has political economy any pretension to the character of a science. So far as rents, profits, wages, prices, are determined by competition, laws may be assigned for them. Assume competition to be their exclusive regulator, and principles of broad generality and scientific precision may be laid down, according to which they will be regulated.”

John Stuart Mill, Principles of Political Economy, London: Parker, 1848, 242

Two ideas that play an important role in competition theory differentiate it from price theory and the prevalent industrial economics: the idea that competition is an evolutionary process and the idea that competition is a rule-guided steering mechanism. The main aim of this article is to investigate how these ideas can be made fruitful for antitrust analysis. Since both ideas have empirical content, but at the same time possess a normative dimension, an antitrust model for the purposes of competition policy must include both scientific knowledge of the way the competitive mechanism functions and considerations of how to deal with norms. I will thus first elucidate the empirical foundations (part 2), before I deal with the normative aspects (part 3). I will then sketch out the main features of the institutional-evolutionary antitrust model (part 4) and finish up with a conclusion (part 5).

\section{The empirical foundations of the IE Antitrust Model}

\subsection{Competition as an Evolutionary Process}

The microeconomic discussion of the last decades has shown that the analysis of the allocation of resources, the traditional focal point of neoclassical market analysis, is not encompassing enough and cannot adequately comprehend real processes of competition. Since the marginalist revolution, microeconomic theory has concentrated on economic decisions and acts of choice in order to explain exchange, prices and the allocation of resources. This neoclassical analysis - even in its current game-theoretic form (e.g. Kreps, 1990) - only partially explains real market occurrences. It fails to recognize or it unduly simplifies the central role of innovation and imitation processes and, accordingly, innovative knowledge. 
By contrast, it is constitutive for competition theory ${ }^{1}$ that the creative activities of firms permanently generate endogenous innovation on the market. This evolutionary perspective is concretely developed in three stands of theory:

(i) Competition as an innovation imitation process (Schumpeterian approaches). The theory of dynamic competition was purposively generated as an alternative to the neoclassical theory of competition. The analysis of the entrepreneur as the key figure and the motor of economic development and the accent placed on the endogenous transition of market structures in the competitive process of creative destruction - both Schumpeterian ideas (Schumpeter 1911; 1942) - have led to a series of well-developed theories, which present a serious alternative to the prevalent understanding of competition as an allocation mechanism. J.M. Clark's modeling of competition as a dynamic process of "moves and responses” (1954/1961) rebuffs the neoclassic view of competition and places process and dynamism in the foreground rather than equilibrium and comparative statics. In modern Schumpeterian approaches it is dynamic competition that leads to increased productivity over time (Porter, 2002; Evans and Schmalensee 2001) and modern evolutionary economics analyses how competition gives rise to the growth of knowledge in markets (Eliasson, Green and McCann 1998).

In our context, it is especially interesting that the theoretical analysis of competition as an innovation-imitation process allows the problem of market power to be viewed under a different light than is possible in the standard neo-classical analysis. The temporary creation of market power positions through innovation is a component of the competitive process, and short-run monopoly profits are important stimuli to innovation, without which the entire process would come to a standstill. Competition thus leads to a permanent forming, shifting and erosion of market power. This is an important building block for the antitrust model that is to be developed.

(ii) Competition as a discovery procedure (Hayekian Approaches). In Hayekian works the knowledge problematic is generalized and the significance of knowledge for the economic order is analyzed. Because individuals in a society do not have complete knowledge of all relevant data, the central problem of economic theory is " $[\ldots]$ how the spontaneous interaction of a number of people, each possessing only bits of knowledge, brings about a state of affairs in which prices correspond to costs, etc. [...]" (Hayek, 1948, p. 50f.). As a process of discovery, competition entails a diffusion of knowledge, which allows all circumstances relevant for economic decision-making to emerge: “[...] which goods are scarce goods, or which things are goods, and how scarce or valuable they are - these are precisely the things which competition has to discover. Provisional

1 For an overview, see Mantzavinos (1994). 
results form the market process at each stage alone tell individuals what to look for" (Hayek, 1978, 181). This view of competition has been further studied within the framework of modern Austrian Economics, which also critically discussed whether competition as a process of discovery tends towards equilibrium (e.g. Kirzner 1992, 1997) or whether, as the so-called radical subjectivists argue, it is a continuous process, without a beginning or an end, which is kept in motion both by unexpected changes and inconsistencies in people's plans (e.g. Shackle 1972/1992, Lachmann 1976, 1986).

What is most important for our purposes is the methodological discussion that has been triggered by the conceptualization of competition as a discovery procedure. The fact that, as Hayek suggested, ${ }^{2}$ only 'explanations of the principle' and 'pattern predictions' are possible in economics and the other social sciences does not mean that we do not avail of genuine law-like statements (Mantzavinos, 1994, ch. 10). Rather, explanations of the principle and pattern predictions are impossible without nomological hypotheses - and indeed, for the simple reason that no explanatory schema can be complete without law-like statements. ${ }^{3}$ The reason for limiting the epistemological claim to explanations of principle is that, while nomological hypotheses about the way that competition functions are certainly possible, given the complexity of the phenomenon, they can only be of limited empirical content. Formulated differently and more simply: It is completely possible to develop and test theories about the phenomenon of competition, but they are not able to boast of a great deal of informational content. Less information is thus available about the structure of this phenomenon than would be available were the phenomenon less complex. This is the methodological building block that we will use in constructing the institutional-evolutionary antitrust model.

(iii) Variation-Selection Arguments. With the help of argumentation based on variation and selection, the analysis of competition processes has become increasingly important. The central theoretical idea here is that competition is to be modeled as an evolutionary process of random variation and selective retention. ${ }^{4}$ In the competition process, the continual introduction of novelty guarantees variety. For its part, the continual introduction of novelty results from the creative actions of the market participants. These kinds of approaches primarily stress the role of heterogeneity in the organizational routines and in the productive technologies of firms (e.g. Nelson and Winter

2 See Hayek's classic essays on "Degrees of Explanation" and on "The Theory of Complex Phenomena" in Hayek (1967, pp. 3-21 and pp. 22-42).

3 For details about this 'covering-law' model of scientific explanation, see the classic work of Hempel (1965). For a review of modern accounts see Psillos (2003).

4 This sort of argumentation often takes the form of analogies to the mechanisms of biological evolution. Most approaches contain the basic thesis that Campbell $(1974 / 1987,56)$ concisely and precisely termed the "blind-variation-and-selective-retention process", which incorporates three core principles: a) a mechanism for introducing variation; b) consistent selection processes; and c) a mechanism for preserving and/or propagating the selected variations. 
1982, Cantner and Hanusch 2001). They also show how companies approach technological problems and how they make non-optimal decisions (Rosenberg, 1994). The basic conceptual apparatus of the models based on variation and selection can be clarified with the help of the 'population approach' ${ }^{5}$ In contrast to Marshall's conception of a representative firm, which is constitutive of neoclassical market analysis, ${ }^{6}$ one starts with a population consisting of different firms with different characteristics or traits that are distributed with a certain frequency. Because new characteristics continually appear in the population, new variations are continually generated. Selection works as those traits that are relatively more successful in securing rewards from the environment increase systematically over time. ${ }^{7}$

What is most important in our context is that such a view of competition stresses the decisive role of the individual more consistently than the neoclassical view of competition. Population thinking is not only individualistic in maintaining that changes at the micro level determine the aggregate results at the macro level; it is also individualistic in maintaining something much more important for economic policy - namely, that the individuality, creativity and distinctness of individuals in the population is never lost sight of in the general argument. Only individuals and organized collectives (above all

5 The most important presentation of population thinking was in the work of the biologist Ernst Mayr (1976, 26-29; 1982 und 1985a, S. 766ff und 2001, 75ff), where its consequences for biology were clearly worked out. See, for example, Mayr $(1982,46)$ : "Western thinking for more than two thousand years after Plato was dominated by essentialism. It was not until the nineteenth century that a new and different way of thinking about nature began to spread, so-called population thinking. What is population thinking und how does it differ from essentialism? Population thinkers stress the uniqueness of everything in the organic world. What is important for them is the individual, not the type. They emphasize that every individual in sexually reproducing species is uniquely different from all others, with much individuality even existing in uniparentally reproducing ones. There is no 'typical' individual, and mean values are abstractions. Much of what in the past has been designated in biology as 'classes' are populations consisting of unique individuals.” See Marshall (1920, 264f.) for the characteristic way he eliminates variety in favor of a "representative firm': “[A]nd for this purpose we shall have to study the expenses of a representative producer for that aggregate volume. On the one hand we shall not want to select some new producer just struggling into business, who works under many disadvantages, and has to be content for a time with little or no profits, but who is satisfied with the fact that he is establishing a connection and taking the first steps towards building up a successful business; nor on the other hand shall we want to take a firm which by exceptionally long-sustained ability and good fortune has got together a vast business, and huge well-ordered workshops that give it a superiority over almost all its rivals. But our representative firm must be one which has had a fairly long-life, and fair success, which is managed with normal ability, and which has normal access to the economies, external and internal, which belong to that aggregate volume of production; account being taken of the class of goods produced, the conditions of marketing them and the economic environment generally."

$7 \quad$ See Metcalfe (1989, 55f.): “The fundamental point here is that the evolutionary framework is concerned with frequencies of events and phenomena rather than with ideal, representative types and there is considerable shift in intellectual orientation in this change of emphasis. [...] The shift from analysing ideal cases to examining frequencies and their distribution is central to the elaboration of an evolutionary perspective of the sort we are proposing. The shift from classical to distributional modes of explanation has occurred in biology in terms of the shift from typological to population thinking about species.” 
organizations) are real, while averages or other aggregates that are found in the neoclassical theory of competition are analytical constructs that do not exist as real entities. This elementary fact is of major significance for the construction of an antitrust model, as will be shown in section three.

\subsection{Institutionally Constrained Competition}

Besides emphasizing the evolutionary dimension of the competitive process, the theory of competition also elaborates on the way that the institutional framework affects competition. Thus, the second major characteristic differentiating it from mainstream microeconomic analysis consists of its systematic integration of the institutional framework. Traditional price theory does not deny that competition is always constrained by rules. It assumes, however, that the definition and execution of property rights are exogenous, and it concentrates on describing market forms and market structures and their effects on economic behavior. Like the assumption of the elimination of novelty, this assumption has proven to be an unfruitful simplification of the competitive process.

This ceteris paribus clause of traditional price theory is impermissible, because of the simple fact that economic behavior is not determined exclusively, or even primarily, by the market form or the market structure. When consumers and entrepreneurs begin participating in and exchanging on the market and competing with each other, they are already socialized individuals, sharing a large number of social rules. Market participants are not a-historical creatures with ordered preferences, who maximize their utility under price and income constraints.

During the socialization processes, the individuals who later become the entrepreneurs of the economic theory have learnt the conventions, moral rules and social norms of the society in which they live. When founding companies, the entrepreneurs are already familiar with the legal rules, and they have learned the degree to which the state protects or infringes on their property rights. They are already the "legal persons" of legal theory. Because they have gone through the same learning history, the entrepreneurs share the same formal and informal institutions, i.e. the rules of the competitive game that make them the specific actors of the specific economic game they are engaged in (Mantzavinos, North and Shariq, 2004).

The systematic integration of the institutional framework into the study of the competitive process has led to a series of insights, which are also useful for purposes of economic policy. The specification and enforcement of property rights (Weimar 1997) also determine what actions are permitted the economic subjects in the competition process, 
i.e. which parameters are allowed and which are not. ${ }^{8}$ Property rights fix the infringements into the spheres of others that individuals are allowed, and they establish which of the possible actions of economic subjects are permitted, and which are not. The antitrust rules subdivide the action parameters into permitted (e.g. price, amount, etc.) and prohibited ones (fraud, theft, cigarette advertisements in television, etc). By this, the institutions define the 'content' of competition: Economic agents are driven by the incentives rooted in the institutions to focus on those activities which are allowed. In the competitive process, then, innovation and imitation can only take place in connection with the employment of certain action parameters only. Hence, by allowing the economic agents only limited action parameters, the institutions simultaneously determine which types of knowledge they will test and obtain. In this way, the institutions channel the innovative potential of the individuals in a certain direction.

If the institutional structure allowed sea piracy, for example, private entrepreneurs would use knifes and guns as action parameters in their effort to attain rents and would consequently acquire all the skills and knowledge necessary for these activities. As a result, in their attempt to acquire profits, the suitable skills would be developed over time (North, 1990, 77). Or to take a more modern example, if companies were allowed to gather trade secrets from one another, company espionage would become a normal action parameter in competition - at least in branches in which the early knowledge of the competitive action of one's competitors is of decisive importance. To successfully engage in such espionage, resources would have to be employed and concrete problemsolving skills would have to be developed.

Beyond this, institutions also determine the speed of competitive processes. The dynamics of the competitive process depend on the rate at which innovations are made and adopted. This, in turn, depends on the payoffs, that is, on the utility increase expected from innovations, and thus, on the incentives to make innovations. The strength of these incentives, however, depends on the institutional framework, which, for its part, can be organized in different ways (Witt, 1987). Thus it is possible to imagine a rule in accord with which the losses that companies incur because of their competitors' innovations would have to be compensated for by the innovative firms. Were such a liability rule introduced (with the compensatory consequences), the incentives for searching for innovative knowledge would decrease considerably, because of the smaller net payoffs from innovations (Witt, 1987, 184 f.). Considerably more important, however, is that,

8 Here it is to be emphasized that not only the formal institutions, but also the informal ones, have this effect. It might be the case that in primitive societies only the informal institutions categorize possible action as permitted and prohibited; and in many developing countries the informal institutions may play the most important role. In modern Western-type democracies, however, in which legal rules are enforced more effectively, it is formal institutions that play the primary role. See Mantzavinos (2001, ch. 7 and 8). 
because of the disappearance of negative sanctions for lagging behind in competition that would result from the compensation, there would no longer be an incentive for imitators to retain up-to-date knowledge (Rosenberg, 1994). Because of this, the incentive to diffuse knowledge quickly would decrease considerably. This being the case, the institutional framework determines not only the content of the competition process, but also the speed of this process.

According to the variation and selection argumentation, the institutional framework can be interpreted as a selection environment for evolutionary competitive processes. The antitrust rules define the criteria for 'success' or 'survival' in the market. ${ }^{9}$ The skills that prevail in the market as 'better' and that are selected as the 'fittest' or 'best adapted' are always determined in relation to these rules. To this extent, the institutional framework channels the evolutionary competitive processes, not by directly determining their outcomes, but by limiting their possible developments.

The insights from institutional economics also throw a different light on the coordination of the plans of economic agents. Standard microeconomic theory traditionally attempts to come to grips with this issue by employing the concept of equilibrium. In general equilibrium theory, activities are ideally related to one another - something that is possible because no innovation takes place in the process of the division of labor. If innovation can be endogenized within the framework of the evolutionary competition theory, then it is necessary to abandon the concept of perfect coordination. That, however, does not mean that coordination becomes impossible. There are rather two levels of the coordination of economic plans: namely, coordination via institutions and coordination via prices. In order for rules to be able to channel the evolutionary competitive process and to fulfill their function at all, the market participants must become familiar with them. As indicated concisely above, this does in fact take place through socialization and the process of collective learning that accompanies it. Thus, not only is the motivational, incentive-establishing aspect of institutions to be taken into consideration; so is the cognitive aspect of them. It is this aspect, which enables economic activities to be coordinated in a fundamental way at an initial level. At a second level, the activities of market participants are coordinated by means of prices. This sort of coordination is imperfect if measured from the framework of a nirvana approach (Demsetz, 1969). From the framework of a comparative approach, however, the crucial point is that economic plans are better coordinated at these two levels within a competitive system than they would be if this system did not exist.

$9 \quad$ For more details, see Mantzavinos (2001, ch. 9). 
In summary, the view of competition as an evolutionary process constrained by rules provides the following building blocks, necessary for the construction of an antitrust model: (i) Because of innovation and imitation, there is a permanent rise and decline of market power positions. (ii) Given the complexity of the research object, scientific statements about the conditions and the effects of evolutionary competitive processes can only possess a low empirical content. (iii) It is creative, diverse and unique individuals who, through variation, keep the competitive process going and factually fuel selection. It is precisely because some things are superior and some inferior that selection can occur at all. (iv) The evolutionary competitive process always unfolds within the framework of (informal and) formal rules, which channel it in a particular direction. Depending on the different systems of rules, competition can and will proceed differently.

\section{Normative Foundations of the IE Antitrust Model}

Economic policy debates usually treat normative questions in reference to welfare economics or constitutional economics. Those economists who attempt to defend their normative considerations with the help of some version of welfare economics normally presume that maximizing the satisfaction of the needs of the members of society is the natural objective of economic policy. This objective appears to them to be natural because, since its origins, economics has viewed the wealth and the welfare of society as its research object. The transformation of the empirical explanations of the welfare produced by individuals acting on markets into the theorems of welfare economics possesses, however, a crypto-normative character, because the value judgments that are usually necessary for this transformation are not explicitly stated.

The view that every measure of economic policy ought, in the last analysis, to be justified in reference to the satisfaction of the needs of the social whole (regardless of the kind of concrete formalism of a social welfare function that has been constructed in one way or another) is in essence a utilitarian idea. Although the fiction of a social welfare function has been massively and convincingly criticized, most economists do not want to really admit that this way of thinking has broken down. As Hans Albert, a leading political philosopher in Germany, has noted "In part, this is an understandable reaction, which certainly is connected to the fact that one otherwise believes that one loses one's footing regarding political recommendations; for the idea of maximal satisfaction still appears to those who are used to thinking economically to be essential to solving the problem of justifying the social order and the economic policy. It is rooted in the way of thinking they take for granted: in the economic perspective” (1964/2001, 266f.). 
In the past years, the rejection of utilitarianism and of welfare economics in favor of social contract theory, retaining the economic perspective, has led to the development of modern constitutional economics (Buchanan, 1989, 1991; Brennan and Buchanan, 2001). The economic perspective of this normative conception is founded on the view that people are able to collectively improve their condition by accepting mutual obligations, analogously to the way that exchanging goods or services on markets is able to bring about mutual advantages. Constitutional economics, however, rejects the utilitarian fiction of a social welfare function, which is characteristic for the welfare economics paradigm. Instead, it tries to figure out the fundamental rules that rational and selfinterested individuals would consent to under the conditions of a hypothetical social contract (Buchanan and Tullock, 1962).

Now, it appears that, in comparison to the fiction of an omniscient, omnipotent and good social planner presumed by welfare economics, the presumption of the conceivable voluntary agreement of all people to the rules and principles of their common social life at the constitutional level constitutes a considerable advancement. But here, too, the political vacuum of welfare economics is simply filled with a new fiction. A hypothetical social contract is only a mental construction, which can neither legitimate political decisions nor offer a useful guide to economic policy. The preferences of the citizenry, which are supposed to carry the main burden of legitimation in constitutional economics, as the ultimate 'givens', need to be interpreted if they are to serve as the foundation for action in economic policy. That the constitutional economist should play the role of the authorized interpreter is, however, in no way self-evident. In addition, one should stress that in an open, evolutionary world the preferences of the citizenry are constantly changing, such that speculatively uncovering them should be even more difficult.

There is an even greater difficulty with both welfare economics and constitutional economics, however, which in fact renders them useless for economic policy. This difficulty is related to the basic structure of argumentation in both views, which is determined by one idea that, in the final analysis, underlies all attempts to provide foundations to social orders and political decisions, namely the idea of a positive justification. This is a general philosophical idea, which is operative in both epistemology and the philosophy of science as well as ethics and social philosophy. This idea was formulated by Leibniz as one of the two foundational principles on which the use of reason is based, namely the principle of sufficient reason. ${ }^{10}$ In the current philosophical discussion, this principle has been best worked out as the principle of sufficient justification

10 See Leibniz (1714/1954), where in $\S 31$ and $\S 32$, in addition to the principle of sufficient reason (principium rationis sufficientis), the principle of contradiction is also discussed. 
within the framework of the philosophy of critical rationalism: "always seek an adequate foundation - a sufficient justification - for all your convictions!” (Albert 1985, 14). According to this principle, everything that is asserted requires an adequate foundation, a sufficient justification, recourse to positive reasons.

"In this way, not only are statements and systems open to a final justification; social conditions and orders of all types are, too. What cannot be justified in this way remains problematic and thus non-binding, or it is rejected. As a result, these demands strengthen the tendency for all types of illusionary justifications. The entire process aims to justify that which is to be legitimized by tracing back its validity to a final source, which is so constituted as to be able to claim authority, and which is thus able to confer its authority by means of the logical or quasi-logical procedure in question" (Albert, 1964/2001, 2778f.).

This structure of thought is to be found both in welfare economics and in constitutional economics. In the former, the consumer preferences serve as the ultimate foundation for economic justification, and in the latter, the citizenry's preferences serve as the ultimate 'givens'. If the greatest possible satisfaction of the consumers' needs is considered the crypto-normative objective of welfare economics, which is more or less naturally justified from the economic perspective, the justification strategy in constitutional economics is related to a legitimation, which one is allegedly able to adduce from the action of individuals in a hypothetical situation.

Both welfare economics and constitutional economics present facets of justificatory thinking in social philosophy and economic policy that are bound to lead to dead-ends. The demand for a justification of everything leads to a situation with three alternatives, all of which are unacceptable. This trilemma is called the Münchhausen Trilemma, because of an analogy existing between this problem and one which that baron once had to solve. It involves three options: one has the choice between an infinite regress, a logical circle or a dogmatic suspension of the process at a particular point (Albert, 1985, p.18; Boudon 2001, 22 ff.). The program treated here typically results in dogmatically suspending the argumentation: in welfare economics, at the point where the maximization of the social welfare function is stated to be the quasi-natural and obvious objective, and in constitutional economics, at the point where the citizenry's preferences is proposed to be the final criterion for legitimation. In itself, this dogmatic structure has nothing to do with the utopian character of the fulfillment of the social welfare function or the satisfaction of the citizenry's preferences. The problem of dogmatism is an additional problem, different from the problem of the utopian character of these conceptions. It consists of the fact that the presumed constellations of needs and preferences are thought to be sacrosanct in principle and thus immune to criticism. 
This dogmatism and the Münchhausen Trilemma can only be avoided by substituting the principle of critical examination for the principle of sufficient justification. In accord with this principle, a discussion of the problems of epistemology, ethics and social philosophy need not refer back to ultimate reasons in order to be convincing or 'rational'. Instead, problems that arise in the sphere of cognition or in the sphere of praxis are to be discussed and solved in light of the already existing solutions. Solutions to new types of problems of any sort require creativity and imagination and are not worked out in a social and mental vacuum. The application of the principle of critical examination means that logically constructed solutions are to be creatively discovered, the solutions are to be weighted in reference to certain values and standards, and, on this basis, the preferred solutions to problems are to be decided upon. Solutions are not judged to be good or rational by virtue of being based on certain knowledge or ultimate values. Instead, our solutions in all areas of cognition and action are fallible, but they can be improved by critical discussion.

"The point of the fallibilistic interpretation of rational practices does not consist in proposing a certain inferential procedure - induction, deduction, apportioning, transcendental recourse - nor in defending their certain character, but in the construction of alternative solution proposals and in comparatively evaluating the performance of these, as is thematized in economic thinking” (Albert, 1978, 30).

The construction of alternative solutions always occurs in the context of already existing solutions, whereby one always has to keep in mind that the existing solutions themselves are already a product of a process of cultural evolution (Hayek, 1960). Every time that a solution to a new problem is required, it is to be borne in mind that a body of solutions to problems of the same or a similar type already exists, which has arisen in an evolutionary process of collective learning. Depending on the problem in question, the available pool of solutions can make it easier or more difficult to find a solution. It defines, in any case, the specific problem-solving context for new problems. For the political realm, this means that there are no presuppositionless solutions to problems, but that each and every political action is undertaken in a more or less strongly structured social situation. The institutional a priori is always to be taken into consideration. The application of the principle of critical examination thus ensures that traditional solutions that have been handed down are not necessarily to be accepted; yet, it does not preclude that they perhaps best fulfill the accepted values and criteria, and given that they have stood the test of time they at times may very well be the best available solutions.

This general philosophical principle of the critical examination of fallible solutions enters into the scientific economic policy if it aims to treat economic problems ration- 
ally, rather than to postulate a rational economic order that is to serve as a standard for economic policy. The idea of the immanent rationality or goodness of a certain economic order is a dogma. In contrast, the critical rational method of treating problems of economic policy is a method that tests, modifies and revises the various feasible alternatives with regard to different criteria. In such a scientific economic policy, it is not necessary to formulate value judgments, because the comparative analysis can be carried out as a purely social-technological undertaking. ${ }^{11}$ As an applied science, political economy can only indicate possible courses of action and thus possibilities for how to achieve ends or combinations of ends by employing certain means. To judge the performance of proposed measures, it is only necessary to hypothetically presuppose certain performative criteria, and then investigate the degree to which the proposed measures can fulfill these criteria. ${ }^{12}$ To do this, it is only necessary to analyze matters of fact; the values necessary in order to set up the technological system need only be hypothetically presupposed. Technological systems do not have a normative character because they do not answer the question, "What should we do?" but only the question, "What can be undertaken in order to solve this problem?” Their practical significance consists in providing information about the outcomes of possible courses of action, not in dictating certain types of action. ${ }^{13}$

The transformation of scientific statements into technological systems can thus be accomplished without value judgments, even if it cannot get by without hypothetically presupposing some criteria. This technological transformation requires, however, certain points of view in order to decide which of those statements that can be logically derived from a theoretical system of propositions can be considered as solutions to

11 The kernel of ethical neutrality formulated by Max Weber is (in contrast to some false interpretations) the minimal demand for distinguishing propositions from value judgments. This weak, indeed trivial, as Weber himself calls it, demand (Weber, 1917/1949, 11) is, however, only significant in practical economic policy, whereby the scientific economic policy can concentrate on developing social-technological systems.

12 The rational discussion of the values is for its part also possible, and the principle of critical examination is at work also here. The search for an Archimedean point in ethics and social philosophy is as useless as in epistemology and the philosophy of science. Ethical statements can also be treated as hypotheses rather than dogmas, and then critically discussed, but since this discussion cannot be oriented on the idea of truth, it cannot be carried out with scientific means.

13 Max Weber was the first to develop this (1917/1949, 45): „It would be superfluous to repeat that it is obviously possible and scientifically useful and necessary to establish propositions of the following type: in order to attain the end $\mathrm{x}$ (in economic policy), $\mathrm{y}$ is the only means, or under the conditions b1, b2, and b3, y1, y2, and y3 are the only or the most effective means. It should be emphatically recalled that the possibility of the exact definition of the end sought for is a prerequisite to the formulation of the problem. Hence it is simply a question of inverting causal propositions; in other words, it is a purely ,technical' problem. It is indeed on this account that science is not compelled to formulate these technical teleological propositions in any form other than that of simple causal propositions, e.g. $\mathrm{x}$ is produced by $\mathrm{y}$, or $\mathrm{x}$, under conditions b1, b2, and b3 is produced by y1, y2, and y3 For these say exactly the same thing, and the ,man of action' can derive his ,prescriptions' from them quite easily.“ 
problems at all. As is generally known from logic, a theory has innumerable consequences and is normally formulated without reference to particular practical problems. Besides, the set of possible inferences from a theory is so large that the implications and consequently the practically relevant consequences of the theory cannot be easily known in advance. In setting up technological systems within the framework of a scientific economic policy, the issue is thus to precisely specify the problem and to point to the viewpoint that is most essential for selecting from among the infinite number of the implications of the theory.

This procedure of technological transformation does not rely on value judgments. Besides, one should clearly distinguish the construction of a technological system and its application in praxis. If technological statements are made the basis of practical behavior - for example, the basis of practical economic policy - it is then of course necessary that value judgments be made about the application at hand. In scientific economic policy, however, which is solely concerned with constructing technological systems, only problems such as the following are treated: How can a central bank best maintain the price stability in a situation which is characterized in such and such a way? Which measures can a government take to decrease the environmental pollution in a country without at the same time triggering negative effects concerning other specific dimensions? Or: What kind of legislation is necessary in order to protect competition?

\section{Main features of the IE Antitrust Model}

\subsection{Protection of Competition by Rule-Guided Competition Policy}

The next step is to show what kind of antitrust model can be built upon the basis of the mentioned empirical findings and normative considerations. It should be clear that such an antitrust model can only be a technological system, to be offered as the basis for action in practical competition policy. In applying this in concrete cases, a whole series of value judgments and decisions are to be made which oblige the constructive imagination of practical economic policy-makers, and which cannot be the object of any scientific analysis. In the following we will presume the "protection of competition" as a hypothetical objective and study how this objective can be best achieved if one sets out from an institutional-evolutionary understanding of competition. The issue is, thus, to answer the question: What can be done, and at what level, to protect competition as a rule-bound evolutionary process?

Before one answers this question, one ought to quickly call to mind how competition can be protected if one endorses the view of competition of current microeconomic 
theory. Standard microeconomics portrays competition - the object of protection - as an allocation mechanism leading to completely predictable outcomes in the form of a market equilibrium. This idea is defended in three theoretical variations: (i) In the traditional price theory, the behavior of competitors is completely determined by the market form, which is presumed to be exogenous. (ii) In industrial economics, the market structure replaces the market form, and competition is analyzed with the help of the "Structure-Conduct-Performance” paradigm (Scherer/Ross, 1990). (iii) In the game-theoretic reformulation of competitive behavior, it is presumed that the market participants have common knowledge of the rules of the game and consequently of the respective market situation (Tirole, 1988). In essence, all of these approaches share the thesis that competition, unfolding within theoretically negligible rules, leads to clearly determined outcomes. Accordingly, competition is protected if it is assured that the production factors are efficiently used given the available knowledge - or, in other words, if care is taken that an optimal allocation of resources prevails in the end.

Fifty years of empirical research within the framework of industrial economics have, however, not been able to prove the existence of a clear causal connection between market forms or market structure and market behavior; neither have they shown that it is possible to adequately determine market outcomes without explicitly introducing the effects of institutions into the analysis (Mantzavinos, 1994, 35ff.). In the words of Richard Schmalensee of already fifteen years ago $(1989,259)$ "derived market structure is clearly affected by market conduct in the long run", and thus "all variables that have been employed in such studies are logically endogenous". Given the failure of the Structure-Conduct-Performance paradigm, the corresponding proposals for the protection of competition are robbed of their nomological basis, and it appears even more necessary to work out an alternative.

The institutional-evolutionary view of competition pushes into the foreground the causal connections between institutions and market behavior. Since the causal effect of market forms or market structures on market behavior cannot be considered to be empirically secure, it appears advisable to focus on the causal effects of institutions on the behavior of market participants. That ought not mean that it will not be shown sometime in the future that certain institutions, by their channeling effect, bring forth certain market structures or market forms, which then lead to specific market outcomes. But as long as it is clear, as it now is, that in the evolutionary competition process, innovative behavior on the part of the market participants can endogenously change the market structure, and thus that causality often runs in the opposite direction - namely, from market behavior to market structures - it is necessary to be content with a theory which has, on the one hand, less empirical content, but is, on the other hand, more corroborated. 
Insofar, one of the building blocks worked out in section two now takes effect; namely, the methodological point that, given the complexity of the phenomenon, empirical statements about the conditions and effects of the evolutionary competitive process can only possess low empirical content. In our context, it follows from this view that it is mandatory to focus on the ways the rules affect the channeling of the competitive process. One can thus formulate the respective technological statement in the following way: it is only possible to protect competition by ensuring that the appropriate rules prevail, guaranteeing the competitive behavior of the participants. The first reason that competition policy ought to focus on the rules of the competition game is purely methodological: At this level only do we possess the nomological knowledge necessary to protect competition. Or put differently: competition policy ought to be active at the level of rules because it is only at this level that the desired goal - namely of protecting competition - can be reached at all. One ought to expect of competition policy only what it is capable of bringing forth. And competition policy can only be efficacious if the necessary empirical hypotheses are available; and this is the case only in respect to the causal effect of certain rules (and not of certain market structures) on competitive behavior.

The second reason for a rule-guided competition policy has to do with what the political economy of regulation teaches us (Stigler, 1988 Mueller, 2003 ch. 15). Anti-cartel and regulation agencies are the object of lobbying activities of the interest groups of various industries. These activities are often successful, so that, independently of the question of whether regulation agencies avail of the necessary governance knowledge, the fact that they often give in to lobbyists is itself a serious problem. If one has the goal of 'protecting competition', it is necessary to see to it that those who are authorized to accomplish this task are able and willing to carry it out. In the case of modern Western-type industrial societies, these are usually anti-cartel officials, who are to some extent dependent politically and susceptible to pressure from interest groups: This is a further reason for competition policy to concentrate on the level of rules.

The competitive mechanism is thus not to be viewed in connection with an ideal model of the rational allocation of resources, whose immanent rationality could supposedly justify an optimal standard for judging market structure and market behavior. Instead, due to the theoretical deficit and the lack of governance knowledge, on the one hand, and the susceptibility of regulation agencies to the lobbying activity of the industry, on the other, steering the process of competition by the means of rules is to be preferred. Such steering at the level of rules is free of ideological justification attempts because it does not operate with utopian optimization arguments; and it is preferable because the critical testing of empirical arguments shows that the competitive mechanism can only be protected at this level. 


\subsection{Per se Prohibitions and Rule-Guided Competition Policy}

The arguments introduced above against a discretionary competition policy, which greatly relies on the specifics of the individual cases, and the general arguments in favor of a rule-guided competition policy do not yet answer the question regarding the type of rules: Which specific characteristics must the rules of the competition policy have in order to best protect competition? The competition rules must be formulated as prohibitions. They thus should only specify what the agents are not allowed to do (Hayek, 1969, 115); this will allow them the freedom to act in accord with their personal goals within the constraints established by the rules. ${ }^{14}$ This preserves both the possibility of innovation and the openness of the evolutionary competition processes. As long as rules are negatively formulated and thus permit any type of action that is not prohibited, the possibilities for action that are open in principle remain infinite. Innovation is thus not blocked, because the negative rules still leave enough possibilities for action open should a change in the relative price motivate a search for new activities. ${ }^{15}$

Per se prohibitions are thus advisable, since a nomocratic rather than a teleocratic view of competition is relevant here. If competition is examined as an allocation machine, which teleologically leads to certain completely foreseeable outcomes, then the demand for per se prohibitions seems unnecessary. It is only if one has a nomocratic understanding of competition, and presumes that competition always proceeds in accord with rules, that the per se prohibitions seem sensible at all, because of their operationability, justiciability and the provision of greater legal security to market participants. Presupposing that competition should be protected, the nomocratic-evolutionary understanding of competition thus leads to the demand for per se prohibitions.

From the perspective of an evolutionary economic policy, ${ }^{16}$ however, per se prohibitions, as instruments for protecting competition, conceal a problem: If one presumes that the process of changing rules is also evolutionary, and thus that new knowledge is also always brought forth at this level, then one can expect that new knowledge about competitive behavior will also arise. The technological transformation of this new knowledge about the effect of rules on market behavior must also, in the course of its use for competition policy, lead to a change in the relevant per se prohibitions. This, however, runs counter to the requirement of the long-term validity of per se rules.

14 See Hayek (1976, 36f.): "Rules which are end-independent, in the sense that they are not confined to those following particular designated purposes, can also never fully determine a particular action but only limit the range of permitted kinds of action and leave the decision on the particular action to be taken by the actor in the light of his ends."

15 For a detailed and at times critical view, see Wegner (2002, 12ff.).

16 For example, see Pelikan and Wegner (2003). 
This problematic of the revision of per se rules over time entails a complex of questions. Treating it would take us far afield. From the perspective of a comparative analysis, the following can be nevertheless construed: In the arena of real political processes, among other things, rules about the protection of competition are also periodically drafted, discussed, passed and implemented. A scientific economic policy must thus also take the (further) empirical fact into consideration, i.e. that at least in modern Western-type democracies, periodic changes in cartel law are to be expected. Thus, on these occasions it is in fact possible that the empirical knowledge available at the respective moment of time will be practically applied in the public and parliamentary debate when passing the new legislation. In the choice between the real existing alternatives, e.g. between the revision of per se prohibitions or the revision of an instrument for discretionary interventions, if the goal is to protect competition, the first alternative is always to be preferred for the reasons stated above.

The literature sees a further problem regarding economic policy that is exclusively or predominantly oriented towards per se prohibitions, namely, that there are hardly any modes of behavior that, from a competition policy perspective, are to be judged negatively under all circumstances. Thus, for example, strategic alliances and contractual arrangements between firms in the research and development of new products are often needed to make innovations possible in the first place (Jorde and Teece, 1991). It thus appears that market behavior cannot be judged ex ante as limiting competition, but usually, or often, only after the economic power that is behind it is also taken into consideration. That is the reason for the objection that it is not possible to diagnose and exactly locate economic power, as is needed to classify market behavior as limiting competition, were there relatively inflexible per se prohibitions. A question thus arises about whether other types of rules might not more effectively protect competition.

An answer to this objection is provided by the second building block that results from the evolutionary point of view: Due to the endogenous generation of innovations and imitations, a permanent rise and decline of market power takes place during the competition process. If one takes seriously the idea that entrepreneurs are creative when using their action parameters in the competitive process, it must be presumed that continual innovations will take place in the employment of the action parameters, and correspondingly, that market positions will permanently shift. If one realistically also takes into consideration that (in the case of a trade policy that is aimed at open markets) potential competition is always possible, both domestically and from abroad, then a monopoly of resources remains the only source of real market power. Although it is in principle already questionable whether monopolizing the access to resources, which indeed constitutes a case of enduring, long-term market power, can be undertaken by any actor other than the government, this in itself does not serve as an argument against the use of 
per se prohibitions. Namely, it is possible to formulate, as a general prohibition, the rule that no individual, no organization and no government are to be allowed to block the access to resources from the remaining competitors. Besides, it is important to stress that, from an evolutionary point of view, resources are not exogenously given, but can always be developed in the production process. The problem can thus in essence be limited to the area of natural resources, that is, to sources of raw materials.

\subsection{The Protection of Competition as a Minimal Demand of the IE Anti- trust Model}

The view that competition is a process, which it is possible to steer with per se prohibitions, offers a fundamentally different model for competition policy than the equilibrium view in accord with which competition - when precisely steered - is able to bring about concrete results. If the case of optimality and the related thoughts of 'market imperfections' and 'second-best solutions' are discarded once and for all, then a comparative approach employing the alternatives of 'competition' and 'no competition' seems to be the only reasonable mode of evaluation. Per se prohibitions need not determine in every concrete case that competition is as perfect, workable or efficient as possible, but merely that competition prevails on the market in general.

This minimalism is not to be understood normatively, i.e. as a demand on competitive policy; it is instead to be understood as a statement about real possibilities resulting directly from the above outlined view of competition: If populations of individual characteristics are varied and selected in evolutionary competition, then the only concern can be to systematically prohibit certain types of individual behavior and, by so doing, to inhibit the differential reproduction of certain characteristics. With this in mind, the third building block that has been worked out applies; namely, that competition can only be protected by seeing to it that creative individuals do not engage in certain types of action. The protection of competition and the protection of individual spheres of action are two sides of the same coin.

The question of the concrete boundaries that ought to be drawn between the spheres of possible action must be more deeply analyzed and more concretely specified than is possible within the framework of this short paper. Here it is only to be emphasized that it is not possible to provide a general model able to serve as a reference for competitive action, which applies to all times and conditions. Rather, the concrete specification of per se prohibitions must proceed from a critical analysis of the prevailing situation, and it must get by without an a-temporal abstract ideal. 


\section{Conclusion}

In this article I have undertaken to develop the main features of a model for competition policy, which takes seriously the evolutionary character of a competition process that unfolds within rules. In order to construct an antitrust model one does not only need empirical knowledge; one must also consider how to adequately deal with norms. It has been shown that, both regarding the economic knowledge about the phenomenon of competition and regarding the normative foundations, the Institutional-Evolutionary Antitrust Model leads to systematically different outcomes and conclusions than the dominant antitrust ideals. A practical competition policy based on the model designed here would not only utilize different instruments, but also, and probably more importantly, it would set different priorities. 


\section{References}

Albert, H. (1964/2001). Rationalität und Wirtschaftsordnung. Grundlagenprobleme einer rationalen Ordnungspolitik. In Gestaltungsprobleme der Weltwirtschaft. Festschrift für Andreas Predöhl, Göttingen.. Reprinted in Lesebuch, 264-302. Tübingen: J.C.B. Mohr (Paul Siebeck).

Albert, H. (1985). Treatise on Critical Reason. Princeton: Princeton University Press.

Albert, H. (1979). Traktat über rationale Praxis. Tübingen: J.C.B. Mohr (Paul Siebeck).

Boudon, R. (2001). The Origin of Values. New Brunswick: Transaction Publishers.

Brennan, G. and Buchanan, J. M. (2001). The Reason of Rules: Constitutional Political Economy. Indianapolis: Liberty Fund.

Buchanan, J. M. and Tullock G. (1962). The Calculus of Consent. Ann Arbor, University of Michigan Press.

Buchanan, J. M. (1989). Explorations into Constitutional Economics. College Station: Texas A\&M University Press.

Buchanan, J. M. (1991). The Economics and the Ethics of Constitutional Order. Ann Arbor: University of Michigan Press.

Campbell, D. T. (1974). Evolutionary Epistemology. 1987. Reprinted in G. Radnitzky and W.W. Bartley III (Eds.), Evolutionary Epistemology, Rationality and the Sociology of Knowledge, 48-114. La Salle, Ill: Open Court.

Cantner, U. and Hansch, H. (2001). Heterogeneity and evolutionary change: empirical conception, findings and unresolved issues. In J. Foster and St. Metcalfe (Eds.), Frontiers of Evolutionary Economics, 228-269. Cheltenham: Edward Elgar.

Clark, J. M. (1954). Competition and the Objectives of Government Policy. In E. H. Chamberlin (Ed.), Monopoly and Competition and their Regulation, 317-337. London: McMillan.

Clark, J. M. (1961). Competition as a Dynamic Process. Washington, D.C.: The Brookings Institute.

Demsetz, H. (1969). Information and Efficiency: Another Viewpoint. Journal of Law and Economics 12: 1-22.

Eliasson, G., Green, Chr. and McCann Jr., Ch. R. (Eds.). (1998). Microfoundations of Economic Growth. Ann Arbor: University of Michigan Press.

Evans, D. S. and Schmalensee, R. (2001). Some Economic Aspects of Antitrust Analysis in Dynamically Competitive Industries. NBER Working Paper 8268. 
Hayek, F. A. von. (1948). Individualism and Economic Order. Chicago: The University of Chicago Press.

Hayek, F. A. von (1960). The Constitution of Liberty. London: Routledge.

Hayek, F. A. von (1967). Studies in Philosophy, Politics and Economics. London: Routledge.

Hayek, F. A. von (1976). The Mirage of Social Justice. London: Routledge.

Hayek, F. A. von (1978). New Studies in Philosophy, Politics, Economics and the History of Ideas. London: Routledge.

Hempel, C. (1965). Aspects of Scientific Explanation. New York: Free Press.

Jorde, Th. M. and Teece, D. (1991). Antitrust Policy and Innovation: Taking account of Performance Competition and Competitor Cooperation. Journal of Institutional and Theoretical Economics 147: 118-144.

Kirzner, I. (1992). The Meaning of Market Process. London and New York: Routledge.

Kirzner, I. (1997). Entrepreneurial Discovery and the Competitive Market Process: An Austrian Approach. Journal of Economic Literature 35: 60-85.

Kreps, D. (1990). A Course in Microeconomic Theory. Princeton: Princeton University Press.

Lachmann, L. (1976). From Mises to Shackle: An Essay on Austrian Economics and the Kaleidic Society. Journal of Economic Literature 14: 54-62.

Lachmann, L. (1986). The Market as an Economic Process. Oxford: Blackwell.

Leibniz, G. W. (1714). Monadologie. 1954. Reprint, Stuttgart: Reclam.

Mantzavinos, C. (1994). Wettbewerbstheorie. Eine kritische Auseinandersetzung. (Theory of Competition. A Critical Approach). Berlin: Duncker \& Humboldt.

Mantzavinos, C. (2001). Individuals, Institutions and Markets. Cambridge: Cambridge University Press.

Mantzavinos, C., North, D. C., and Syed, S. (2004). Learning, Institutions and Economic Performance. Perspectives on Politics 2, no. 1: 75-84.

Marshall, A. (1920). Principles of Economics. 8th ed. London: Macmillan Press.

Mayr, E. (1976). Evolution and the Diversity of Life: Selected Essays. Cambridge, Mass: Harvard University Press. 
Mayr, E. (1982). The Growth of Biological Thought. Cambridge, Mass: Harvard University Press.

Mayr, E. (1984). Darwin`s Five Theories of Evolution. In D. Kohn (Ed.), The Darwinian Heritage, 755-772. Princeton: Princeton University Press.

Mayr, E. (2001). What Evolution is. New York: Basic Books.

Metcalfe, St. (1989). Evolution and Economic Change. In Aubrey Silberston (Ed.), Technology and Economic Progress, 54-85. Basingstoke, Hampshire: Macmillan.

Mueller, D. (2003). Public Choice III. Cambridge: Cambridge University Press.

Nelson, R. R., and Winter S. (1982). An Evolutionary Theory of Economic Change. Cambridge/Mass: Harvard University Press, Belknap Press.

North, D. C. (1990). Institutions, Institutional Change and Economic Performance. Cambridge and New York: Cambridge University Press.

Pelikan, P. and Wegner, G. (Eds.) (2003). The Evolutionary Analysis of Economic Policy. Cheltenham: Edward Elgar.

Porter, M. (2002). Competition and Antitrust: A Productivity-Based Approach. Working Paper.

Psillos, St. (2003). Causation and Explanation. McGill-Queens University Press.

Rosenberg, N. (1994). Exploring the Black Box. Cambridge: Cambridge University Press.

Scherer, F. M., and Ross, D. (1990). Industrial Market Structure and Economic Performance. 3rd ed. Boston: Houghton Mifflin.

Schmalensee, R. (1989). Inter-Industry Studies of Structure and Performance. In R. Schmalensee and R. Willig (Eds.), Handbook of Industrial Organization, vol. 2. Amsterdam: Elsevier Science Publishers.

Schumpeter, J. A. (1911). Theory of Economic Development. 1983. Repr. New Brunswick: Transaction Publishers.

Schumpeter, J. A. (1942). Capitalism, Socialism and Democracy. 1950. 3rd ed. New York: Harper.

Shackle, G.L.S. (1972). Epistemics and Economics. 1992. Reprint, New Brunswick, N.J. and London: Transaction Publishers.

Stigler, G. (Ed.) (1988). Chicago Studies in Political Economy. Chicago: The University of Chicago Press. 
Tirole, J. (1988). The Theory of Industrial Organization. Cambridge, Mass: The MIT Press.

Weber, M. (1917/1949). The Meaning of ,Ethical Neutrality' in Sociology and Economics. In E. A. Shils and H. A. Finch (Eds.), Max Weber on The Methodology of the Social Sciences, 1-47. Illinois: The Free Press of Glencoe.

Wegner, G. (2002). Evolutionary Markets and the Design of Institutional Policy. Discussion Paper No.: 2002-010E. Staatswissenschaftliche Fakultät. Universität Erfurt.

Weimer, D. (Ed.) (1997). The Political Economy of Property Rights. Cambridge and New York: Cambridge University Press.

Witt, U. (1987). How Transaction Rights are Shaped to Channel Innovativeness. Journal of Institutional and Theoretical Economics 143: 180-195. 